\title{
Psychometric properties of the Catalan version of the Trait Emotional Intelligence (TEIQue): Comparison between Catalan and English data
}

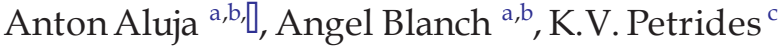 \\ a Department of Psychology, University ofLleida, Catalonia, Spain \\ ${ }^{\mathrm{b}}$ Institute ofBiomedical Research, Lleida, Catalonia, Spain \\ ${ }^{c}$ London Psychometric Laboratory, University College London, UK
}

a rticle in fo

\section{Article history:}

Received 9 March 2016

Received in revised form 26 April 2016

Accepted 30 April 2016

Available online 14 May 2016

\section{Keywords:}

Trait emotional intelligence

TEIQue

Factor analysis

Cross-cultural research $\mathrm{a} b \mathrm{st} \mathrm{r}$ a c t

The present study compared the psychometric properties of the Trait Emotional Intelligence Questionnaire (TEIQue) in Catalan and UK samples. The results showed similar means and standard deviations in the facets scoring higher in both languages, except for Adaptability $(d:-0.50)$ and emotion management $(d:-0.37)$. The alpha reliabilities of the TEIQue facets were similar and acceptable in both samples. The TEIQue alpha was 0.95 and 0.90 in Catalonia and the UK, respectively. All TEIQue facets were highly correlated in both samples, suggesting a coherent construct. The factor structure was investigated through exploratory (EFA) and confirmatory factor analysis (CFA) for 13 and 15 facets respectively. The four-factor theoretical structure was satisfactorily replicated using orthogonal rotation for 13 and 15 facets. Factor congruency coefficients were at, or above, 0.98 for both languages and both solutions (13 and 15 facets). As expected, CFA analyses of the simple structures of the three models yielded unsatisfactory fit indices, although these improved considerably after incorporating secondary loadings and correlated error terms. The cross-cultural stability of the instrument was supported by multigroup analyses. The relationships between TEIQue factors and facets were the same in both countries. The TEIQue psychometric properties were similar and robust in both samples.

(C) 2016 Elsevier Ltd. All rights reserved.

\section{Introduction}

Emotional intelligence (EI) has been broadly studied (Goleman, 1995; Salovey \& Mayer, 1990), with different psychometric measures to assess this construct (Bar-on, 1997; Mayer, Caruso, \& Salovey, 1999; Schutte et al., 1998). The present study focuses on trait emotional intelligence, which is formally defined as a constellation of emotional per- ceptions located at the lower levels of personality (Petrides, 2001; Petrides, Pita, \& Kokkinaki, 2007) and, in particular, its measurement ve- hicle, viz., the Trait Emotional Intelligence Questionnaire (TEIQue; Petrides, 2009).

The TEIQuehas had a wide impact in thepsychological literature for the past 15 years and it has been translated into multiple languages. It was originally developed in England using a large sample ranging from 15 to 77 years old subjects. The TEIQue comprises 153 -items dis- tributed in 15 facets, four domains or factors and a global dimension. The exploratory factorial structure indicates four factors: emotionality (emotion perception, trait empathy, emotion expression and relation- ships), self-control (emotion regulation, stress management, impulse control, adaptability and self-motivation), sociability (assertiveness,

\footnotetext{
* Corresponding author at: Department of Psychology, and University of Lleida, Avda. De l'Estudi General, 4, 25001 Lleida, Catalonia, Spain. E-mail address: aluja@pip.udl.cat (A. Aluja).
} 


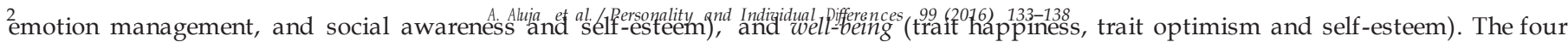
factors are strongly correlated (0.35 to 0.50$)$. Strong sex differences are reported in assertiveness, emotion regulation, relationships, selfesteem facets and self-control, and emotionality factors, but overall they tend to balance out and produce roughly equal scores.

The TEIQue structure has been replicated by Mikolajczak, Luminet, Leroy, and Roy (2007) in Belgium using the same factorial extraction procedure and oblique rotation method. Congruence coefficients of the factor structure (pattern matrix) between Belgian and Englishrange from 0.96 to 0.99 , showing a good factorial equivalence. This factorial exploratory structure has also been replicated and confirmed in Georgia and Hong Kong (Martskvishvili, Arutinov, \& Mestvirishvili, 2013; Gökçen, Furnham, Mavroveli, \& Petrides, 2014). In the threenon-English studies the rotation method of choice has been obliquewith the factorial solution from the pattern matrix, not the structurematrix. The factors of the TEIQue are strongly correlated and the obliquestructure matrix show overlaped variables in all factors.

Freudenthaler, Neubauer, Gabler, Scherl, and Rindermann (2008), performed a CFA of the TEIQue incorporating the correlated errors in the analysis between the following pairs of facets: happiness-optimism, happiness-relationships, assertiveness- empathy, assertiveness-social awareness, and assertiveness- relationships. They obtained acceptable fits indices. More recently,

Jacobs, Sim, and Zimmermann (2015) tested the higher-order factor structure of the TEIQue-SF (short form) with a CFA and after incorporating the correlated error terms (happiness- optimism; self-esteem-social awareness) obtained also an accept- able fit. Marjanovic and Dimitrijevic (2014) also performed a CFA with a Serbian sample, and after incorporating correlated errors (happinessoptimism, emotion expression-social awareness, andempathy-assertiveness) obtained a good fit.

The main objective of the current study was to analyze the psychometric properties of the Catalan version of the TEIQue in a stratified general population by gender and age groups representing a large age cohort (18-86 years old). We were interested in a) gender differences in the facets, b) reliability, c) factorial structure, and d) comparing the factor structure of the Catalan version of the TEIQue with that of an English sample.

\section{Method}

\subsection{Participants}

The Catalan sample consisted of 351 subjects (177 men and 174 women). The mean age was 40.27 (S.D.: 16.00; range: 18-86) for men, and 39.47 (S.D.: 15.26; range: 18-73) for women. Age was strati-fied into four quartiles: 18- 22 (26.3\%), 23-46(25.1\%), 47-51 (23.4\%) and 52-86 $(25.2 \%)$ years old. There were no age differences between genders $(d:-.05)$. All subjects were white European from the general population. They were recruited in the city of Lleida by undergraduate students that collaborated in this study. The students invited to partici- pate in this study subjects from their social context as relatives, neighbors and friends. The data were analyzed as part of an assignment in the course of "Psychology of personality".

The English sample comprised 1666 individuals (907 female, 759 male, 74 unreported). The sex differences analyses were based on 863 females and 729 males $(n=1592)$. The rest of the analyses were based on all 1666 subjects. The mean age for men was 32.67 years (SD: 11.95; range: 16-77) and for women 27.10 (SD: 10.64 range: 16- 74). Most participants were of white UK origin (58\%), followed by white European (19.2\%), Indian (6.6\%), African and Caribbean (5.7\%), and East Asian (5.1\%). Strong age differences were found by sex ( $d$ :

.79). The English sample was the same as in Petrides (2009).

\subsection{Measure description}

The Trait Emotional Intelligence Questionnaire (TEIQue) has 153 items which are rated on a 7-point scale ranging from 1 (strongly dis-agree) to 7 (strongly agree). The TEIQue is structured in 13 facets asser-tiveness, emotion control, emotion expression, emotion management, emotion perception, empathy, happiness, impulse control, optimism,relationships, self-esteem, self-motivation, social awareness and stress management. These facets are grouped into four factors: well-being, self-control, emotionality and sociability. The adaptability and self-motivation facets are not integrated in any of the four factors and areconsidered as auxiliary facets that feed directly into the global EI traitscore (Petrides, 2001; Petrides \& Furnham, 2003). The alpha internalconsistencies of the 20 TEIQue variables (15 facets, 4 factors and theglobal EI trait score) ranged between 0.67 and 0.87 (Petrides, 2009). For details see http://www.psychometriclab.com.

\subsection{Translation procedure}

The TEIQue was translated to Catalan by a Catalan-English bilingual speaker, and back-translated by a professional English-Speaking bilingual translator familiarized with the psychological literature. TheEnglish back-translation was analyzed by the last author and theequivalence between the source and target version was evaluated byall authors. Translation and back-translation procedures were 
3. Results

\subsection{Descriptive, gender differences and alpha reliability}

Appendix 1 shows descriptivestatistics, alphas, and sex differences for 15 facets and 4 factors of the Catalan and English TEIQue versions. In the Catalan sample, women scored relatively higher than men in trait-empathy $(d: 0.40)$ and the Emotionality factor $(d: 0.48)$. Women scored higher in emotional expression $(d: 0.35)$, emotion perception $(d: 0.34)$, and relationships $(d: 0.30)$. In contrast, in the English sample males scored higher in assertiveness $(d:-0.36)$, emotional manage- ment $(d:-0.30)$, emotional regulation $(d:-0.61)$, stress management $(d$ : -0.55$)$, self-esteem $(d:-0.37)$, and in the factors of self-control $(d:-0.57)$ and sociability $(d:-0.36)$. The main differences betweenthe Catalan and English samples were adaptability $(d:-0.50$, and emo- tion management $(d:-0.37)$, where the English scored higher than the Catalans. Alpha reliabilities of the TEIQue facets ranged from 0.59 to 0.87 , and from 0.68 to 0.89 for Catalans and English respectively. The global TEIQue alpha values were 0.95 and 0.90 in each country.

\subsection{TEIQue correlations and exploratory factorial structure}

In Appendix 2, we present the intercorrelation matrix for the 15 TEIQue facets (including the total score) for the Catalan and the English samples. The average of correlations between the 15 facets with the total scores was 0.66 and 0.65 for the Catalan and English samples, respectively. Correlations between the facets were positive and ranged from 0.07 to 0.73 (average 0.39 ) for the Catalan sample, and 0.12 to 0.74 (average 0.46 ) for the English sample. For the Catalan sample the correlations ranged between 0.30 and 0.63 and for the English sample between 0.35 and 0.50 .

Table 1 shows the factorial structure of the 15 and 13-facets for the Catalan and the English samples. A Principal Axis (PA) analysis with orthogonal rotation was used in all samples extracting four factors. For the Catalan data the Kaiser-Meyer-Olkin measures of sample adequacy for the 15 and 13 facets were above 0.88 vs 0.86 and a Bartlets's test of sphericity of 2791.105 vs 2438.70 approximated chi squared (d.f.: 105 vs 78 ; $p$ b 0.001 ). The four factors explained the $69.11 \%$ and $73.423 \%$ of the total variance. For the English data the Kaiser-Meyer-Olkin mea- sures of sample adequacy for the 15 and 13 facets were above 0.90 vs

0.87 and a Bartlets's test of sphericity of $12,648.601$ vs $10,697.356$ approximated chi squared (d.f.: 105 vs $78 ; p$ b $0.001 / 0.001$ ). The four factors explained the $69.12 \%$ and $72.63 \%$ of the total variance.

Correlations between the TEIQue factors and dimensions for the Catalan and English samples were very similar (see Appendix 2). We performed an Orthogonal Procrustes rotation using the Catalan and En-glish structures for 15 and 13 facets. The global Tucker factorial congru-ence coefficients with the English and Catalan 15 facets version weremostly above 0.98 and for English and Catalan 13 facets versions above 0.99 (Table 1).

\subsection{Confirmatory Factorial Analysis}

The Confirmatory Factor Analyses (CFA) of the 15 and 13 TEIQue facets were based in four latent variables with the Maximum Likelihood estimationmethod indifferent models of growing complexity:1) Simple structure one-factor (all facets were linked to their respective four fac-tors and the factors linked to a single latent factor); 2) Simple structure 4-factor: (facets as observed variables linked to 4 factors as latent vari- ables); 3): Simple structure 4-factor and salient loadings (all secondaryloadings larger than \pm .30 ); and 4) Simple structure 4-factor and salient loadings plus correlated errors (higher modifications indices). 
Table 1

Catalan and English TEIQue factor structure comparisons afterprincipal axis analysis and Varimax rotation.

\begin{tabular}{|c|c|c|c|c|c|c|c|c|c|c|c|c|c|c|c|c|c|c|}
\hline & \multicolumn{9}{|c|}{ Factor solution with 15 facets } & \multicolumn{9}{|c|}{ Factor solution with 13 facets } \\
\hline & \multicolumn{4}{|c|}{ Catalan sample } & \multicolumn{5}{|c|}{ English sample } & \multicolumn{4}{|c|}{ Catalan sample } & \multicolumn{5}{|c|}{ English sample } \\
\hline & & 2 & 3 & 4 & & 2 & 3 & 4 & $\mathrm{CC}^{\mathrm{a}}$ & & 2 & 3 & 4 & & & 3 & 4 & $C C^{\mathrm{a}}$ \\
\hline Emotion regulation & .84 & .08 & .05 & .13 & .81 & .17 & .03 & .11 & .99 & .82 & .08 & .06 & .11 & .82 & .18 & .04 & .13 & .99 \\
\hline Stress management & .76 & .14 & .18 & .24 & .73 & .23 & .10 & .24 & .98 & .76 & .14 & .19 & .22 & .72 & .24 & .12 & .26 & .99 \\
\hline Impulse control & .56 & .02 & .12 & .22 & .60 & .01 & .29 & .09 & .96 & .61 & .05 & .13 & .16 & .57 & .03 & .29 & .10 & .97 \\
\hline Adaptability & .35 & .29 & .26 & .31 & .49 & .30 & .24 & .26 & .99 & - & - & - & - & - & - & - & - & \\
\hline Self-motiv ation & .28 & .11 & .23 & .52 & .46 & .23 & .29 & .30 & .93 & - & - & - & - & - & - & - & - & \\
\hline Assertiveness & .14 & .61 & .09 & .33 & .19 & .71 & .11 & .17 & .99 & .15 & .65 & .10 & .28 & .16 & .72 & .11 & .17 & 1 \\
\hline Social awareness & .22 & .63 & .34 & .34 & .28 & .71 & .40 & .20 & 1 & .22 & .63 & .36 & .30 & .24 & .71 & .40 & .21 & 1 \\
\hline Emotion management & -.01 & .79 & .32 & .04 & .07 & .68 & .26 & .09 & .97 & -.01 & .75 & .34 & .05 & .06 & .68 & .26 & .09 & .98 \\
\hline Self-esteem & .31 & .32 & .20 & .64 & .35 & .51 & .17 & .41 & .97 & .34 & .34 & .22 & .60 & .32 & .52 & .17 & .41 & .97 \\
\hline Emotion perception & .17 & .37 & .61 & .26 & .14 & .28 & .68 & .12 & .98 & .18 & .38 & .63 & .20 & .13 & .28 & .69 & .12 & .99 \\
\hline Relationships & .31 & .03 & .64 & .39 & .25 & .03 & .63 & .33 & .99 & .33 & .04 & .65 & .36 & .23 & .03 & .63 & .33 & .99 \\
\hline Empathy & .24 & .28 & .54 & .13 & .18 & .17 & .62 & .06 & .98 & .23 & .26 & .54 & .13 & .15 & .17 & .62 & .06 & .98 \\
\hline Emotion expression & -.06 & .33 & .59 & .27 & .03 & .32 & .62 & .22 & .99 & -.05 & .33 & .60 & .25 & .01 & .34 & .62 & .22 & .99 \\
\hline Happiness & .15 & .17 & .39 & .73 & .21 & .19 & .27 & .83 & 97 & .16 & .16 & .41 & .76 & .18 & .19 & .27 & .84 & .99 \\
\hline Optimism & .32 & .29 & .20 & .70 & .32 & .27 & .19 & .70 & .99 & .33 & .29 & .22 & .69 & .28 & .28 & .20 & .69 & .99 \\
\hline Total Congruency C. & .99 & .98 & .98 & .96 & & & & & .98 & .99 & .99 & .98 & .98 & & & & & .99 \\
\hline Eigenvalue & 1.79 & 1.04 & .97 & 6.59 & 6.48 & 1.60 & 1.29 & 1 & & 5.87 & 1 & 1.76 & .91 & 1.28 & 5.63 & 1.53 & 1 & \\
\hline$\%$ acounted variance & 11.90 & 6.90 & 6.44 & 43.96 & 43.12 & 10.69 & 8.61 & 6.69 & & 45.18 & 7.72 & 13.53 & 6.99 & 9.88 & 43.30 & 11.75 & 7.50 & \\
\hline \multicolumn{19}{|c|}{ TEIQue factor intercorrelations 13 facets factor solution (Catalan/English) } \\
\hline $\begin{array}{l}\text { Factors } \\
\text { Emotionality }\end{array}$ & \multicolumn{5}{|c|}{$\begin{array}{l}\text { Emotionality } \\
\left(.91^{\mathrm{b}} / .94\right)\end{array}$} & \multicolumn{4}{|c|}{ Self-control } & \multicolumn{4}{|c|}{ Sociability } & \multicolumn{5}{|c|}{ Well-being } \\
\hline Self-control & \multicolumn{4}{|c|}{$.36 / .36$} & & \multicolumn{4}{|c|}{$(.96 / .95)$} & \multirow{2}{*}{\multicolumn{4}{|c|}{$(.93 / 94)$}} & & & & & \\
\hline Sociability & \multirow{2}{*}{\multicolumn{4}{|c|}{$\begin{array}{r}.61 / .40 \\
63 / 45\end{array}$}} & & \multicolumn{4}{|c|}{$.30 / .35$} & & & & & & & & & \\
\hline Well-being & $.63 / .45$ & & & & & $.49 / .5$ & & & & \multicolumn{4}{|c|}{$.57 / .45$} & \multicolumn{5}{|c|}{$(.89 / 84)$} \\
\hline
\end{tabular}

Note: loadings higher or equal .30 in boldface.

CC. Congruency coefficients.

${ }^{\mathrm{b}}$ Catalan and English factor-dimensions correlations. $p$ b.001.

Modifications indices improve model fit and have been flagged as po- tential changes that can be made to the model.

Maximum Likelihood Confirmatory Factor Analyses were conducted over the variance-covariance matrices of the 15 and 13 TEIQue facets. Several criteria of model fit were used (see Bollen \& Long, 1993): The standardized root mean square residual (SRMR); the goodness of fit 
index (GFI); the comparative fit index (CFI); the Tucker-Lewis index (TLI) and the root mean square error of approximation (RMSEA). A well-fitting model should ideally have a non-significant $\chi^{2}$ statistic, a SRMR and RMSEA values of 0.05 or lower, and CFI, GFI and TLI values close to 0.95 or greater (Blanch \& Aluja, 2009; Hu \& Bentler, 1995; Mulaik, 2007).

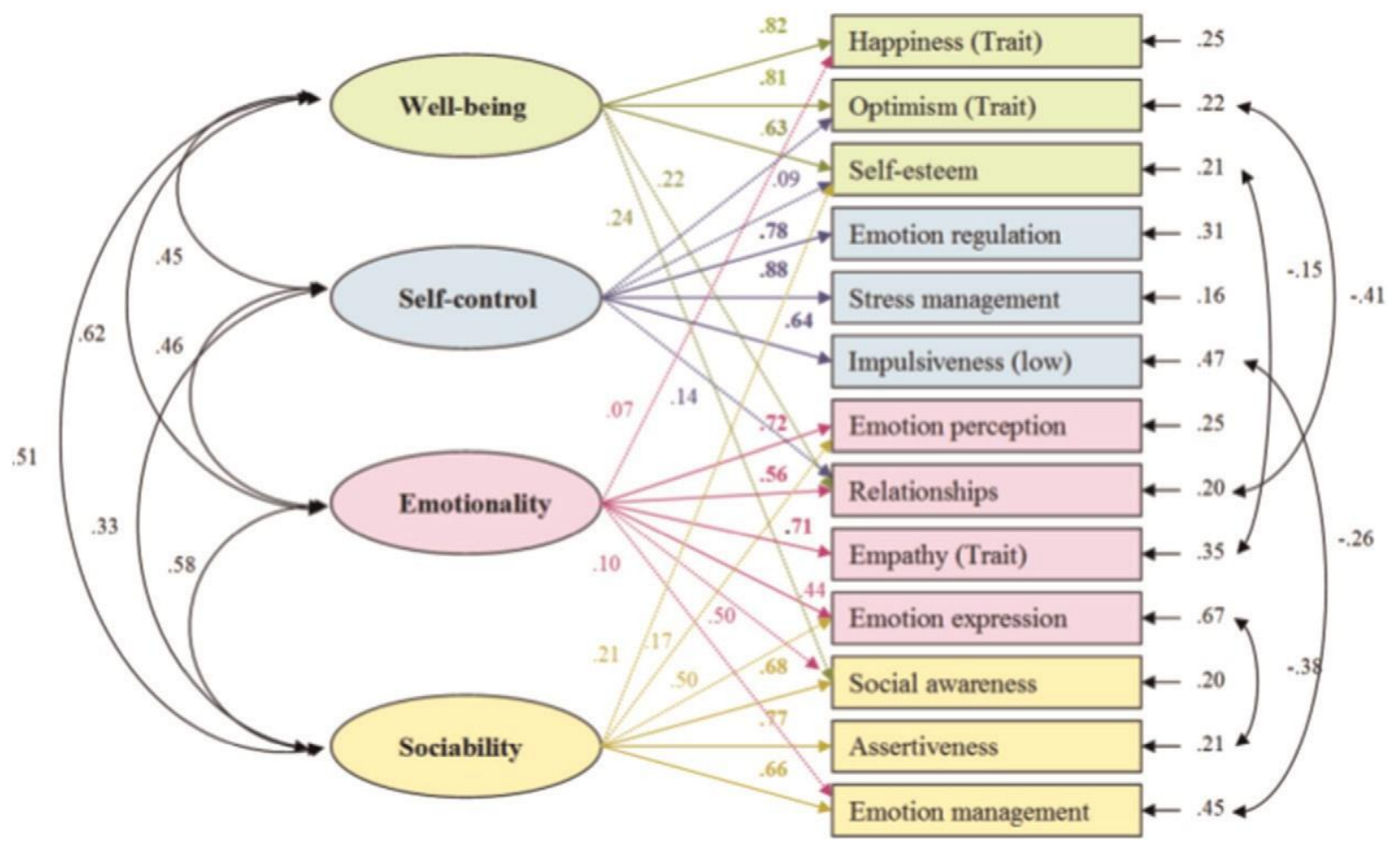

Figure 1.CFA of higher-order factor structure of the TEIQue 13 facets. Catalan version (model 4_factors_SL + r.Standardized estimates). 
Appendix 3 shows the goodness-of-fit indices obtained with the models of the TEIQue when compared with the simple structure for 13 and 15 facets in both countries. The simple structure fit indices of one and four factor models (13 and 15 facets) models were unsatis- factory. Adding secondary loadings equal to or higher than $0.30 \mathrm{im}$ - proved the results, but the goodness-of-fit-indices were only satisfactory when incorporating the error covariance. The correlated facets for the 13-facet model in the Catalan sample were optimism- relationships, selfesteem-empathy, impulsivity-emotion management and emotion expression-assertiveness. The correlated facets for the 13-facet model in the English sample were impulsiveness-relationships, empathy-assertiveness and empathy-emotion management (Figs. 1 and 2 ).

Given that two different models presented the best fit for Catalan and English samples, and with the aim of testing if the same structure could be supported in both samples, a series of multigroup analyses were conducted (Appendix 4). In this case, three models were tested:

1) Multigroup A: The fit of the 4 factors incorporating the salient load-ings and correlated error terms (4_factors_SL + r) model was simultaneously computed in both samples. Note that no restrictions across countries were imposed in this model, 2) Multigroup B: This model test-ed for possible changes in the relationships between latent variables. So, the covariances between the TEIQue factors and between the errorterms included in the 4_factors_SL + r (Figs. 1 and 2) were set equal across the two samples, and 3) Multigroup C: This model alsotested for changes in the loadings of the TEIQue scales on thefactors across countries. Therefore, the factor loadings were fixed to be equal in both countries. The covariances fixed in model B were also fixed in model C, which was consequently nested withinmodel B. Also, Models B a nd C were nested under Model A. The three models were fitted twice: for the Catalan 4_factors_SL + r, and for the English 4 _factors_SL + r.

The results of the multigroup analyses are shown in Appendix 4. As it can be seen, the fit of the multigroup was similar to the results reported on Appendix 3. Fitting this model simultaneously in both countries did not seem to affect its fit. More importantly, when the covariance 


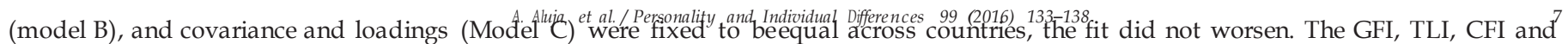
RMSEA were almost equal in the three models. Furthermore, this pat-tern of results emerged for both the Catalan and the English TEIQuedata (Figs. 1 and 2).

\section{Discussion}

This study was designed to investigate the psychometric properties of the Catalan version of the TEIQue and compare them with those from the original English sample. Country and age did not significantly affect the 15 facets and four factors of the TEIQue according to the effect sizes values. Alpha reliabilities were also acceptable and similar to the alphas obtained in the English sample and other published versions in different countries.

The exploratory factor analyses employed orthogonal rotations, contrary to previous studies that used oblique rotations with the pattern, instead of the structure matrices (Freudenthaler et al., 2008; Gökçen et al., 2014; Martskvishvili et al., 2013; Mikolajczak et al., 2007). The pattern matrix was very similar to the matrix obtained by orthogonal rotation. The comparison of both matrices yielded a global congruency coefficient above 0.98 , while the oblique structure matrix yielded strong secondary loadings on different factors. The reason for this is that the TEIQue facets were strongly correlated. The pattern matrix held the facet loadings. Each of its rows is essentially a regression equation, where the standardized observed vari- able is expressed as a function of the factors. The loadings were the regression coefficients. Oblique rotations were better represented in the structure matrix, which also reflected the correlations between the variables and factors (Gorsuch, 1982). With the TEIQue facets strongly correlated, the structure matrix should produce fac- tors with multiple secondary loadings. In our study, we selected the orthogonal rotation to maximize the variance of the squared loadings of a factor on all the variables in the factor matrix.

The results of the exploratory factor analysis were similar for the 15- and 13-facet structures in the Catalan and English samples,

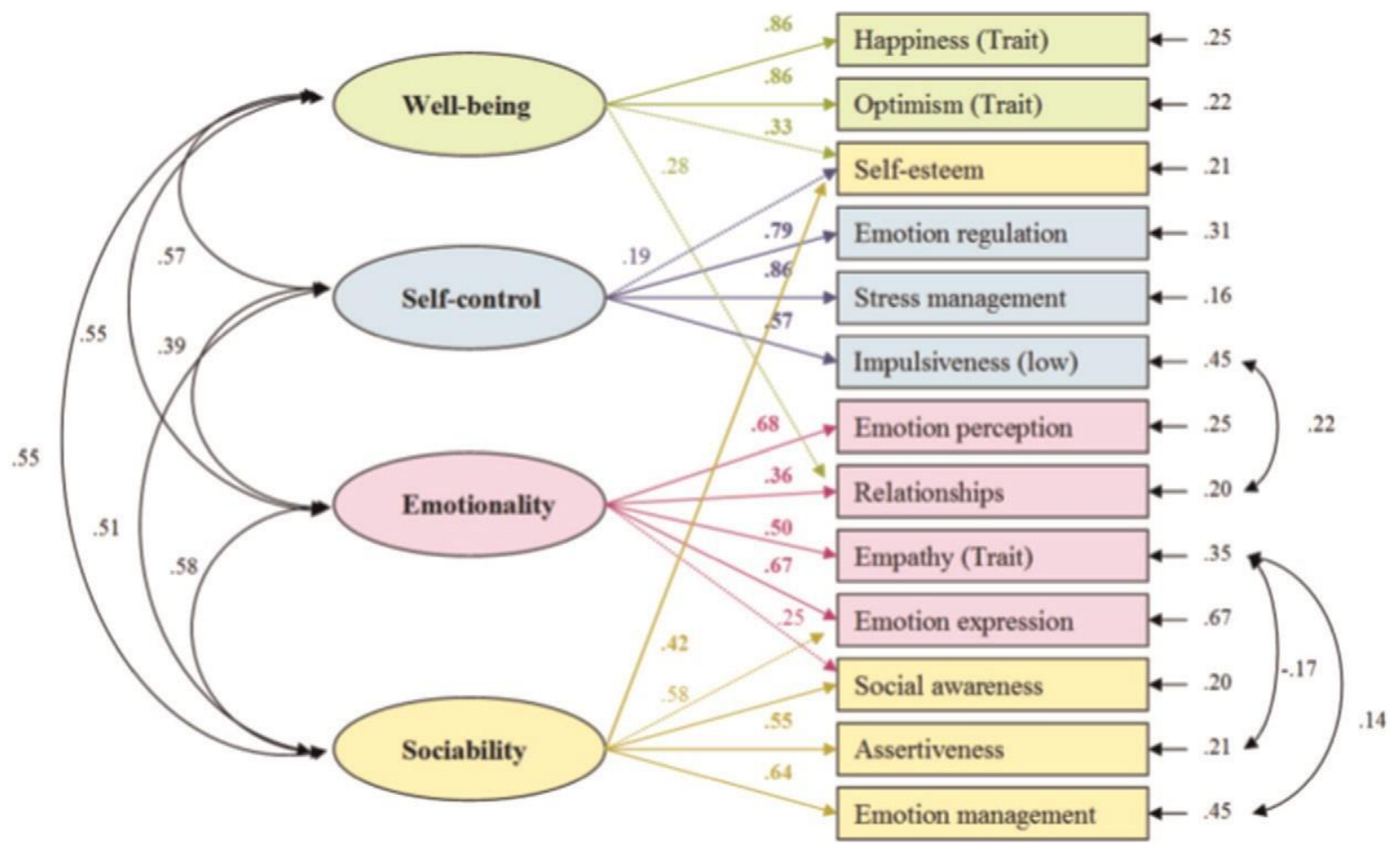

Figure 2. CFA of higher-order factor structure of the TEIQue 13 facets. English version (model 4_factors_SL + r.Standardized estimates). 
demonstrating the cross-cultural stability of the TEIQue as reflected in the high congruency coefficients obtained after the orthogonal Procrustes rotation. The self-esteem facet was placed in the Sociabil- ity factor in the current English sample (also in the original English validation; Petrides, 2009), but in the Well-being factor in the Cata- lan and the Georgian samples (Martskvishvili et al., 2013). The selfesteem facet had also higher secondary loadings in Emotionality fac- tor in the Catalan and English samples. In the French version the selfesteem facet has strong secondary loadings also in the Sociability factor (Mikolajczak et al., 2007). These results suggest a revision of the items of this facet in order to improve its construct validity. The orthogonal Procrustes rotation could be the appropriate strategy to evaluate the factor invariance of personality inventories such as the NEO-PI-R (Gondo, Shimonaka, Nakazato, Ishihara, \& Imuta, 1993; Rolland, Parker, \& Stumpf, 1998; Terracciano, 2003) or the ZKA-PQ (Aluja, Kuhlman, \& Zuckerman, 2010).

This pattern of cross-cultural stability was supported by the mul- tigroup analyses. Both the Catalan and English structures provided a good fit, which indicates that the interrelationships of the TEIQue factors and facets were similar in both countries. In other words, the small differences observed between the Catalan and English models (Figs. 1 and 2, respectively) were of little theoritical relevance. This finding corroborates previous studies suggesting a strong cross-cultural stability of the TEIQue instrument across European and NonEuropean countries, and across different languages (Gökçen et al., 2014; Mikolajczak et al., 2007; Martskvishvili et al., 2013). Sheldon et al. (2004) reported cross-cultural concordance for the construct of Well-Being across North-American, Chinese, Korean and Taiwanese samples, results which are highly congruent with thosereported herein.

Many researchers have noted that it is difficult toobtain good SEM fit indices for multidimensional personality models generated by means of EFA (Aluja et al., 2010; Aluja, García, \& García, 2004;Borkenau \& Ostendorf, 1990; Church \& Burke, 1994; Katigbak, Church,

\& Akamine, 1996; McCrae, Zonderman, Costa, Bond, \& Paunonen, 1996; Petrides, Jackson, Furnham, \& Levine, 2003; Vassend \& Skrondal, 


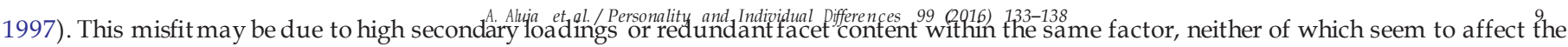
factor structure obtained through EFA procedures.

In our study, several CFA models were analyzed comparing the sim- ple structure of the TEIQue (13- and 15-facet models) with other models that incorporated the secondary factor loadings and the corre- lated errors identified through the modification indices (MI). The results showed that the simple structure for the one and the four-factor models did not fit the data well. According to Church and Burke (1994), our study suggested that the simple structure was unlikely to meet relaxed criteria. One of the causes of this low fit could be the presence of salient non-keyed loadings onseveralfactors.

The fit improved when an alternative model including the same or higher loadings, was specified. The analyses of the MIs indicated that additional correlations among error variances should be added in order to enhance the fit of a particular factor structure. Thus, the model that incorporated the secondary loadings and correlated resid- uals yielded acceptable fit indices. When comparing the different goodnessof-fit indices throughtheCFAs, thesimplestructure4-factor and salient loadings plus the correlated errors model yielded much bet- ter values in both the 13- and 15-facet solutions.

The findings indicate that the Catalan and English TEIQue facets were highly inter-correlated. The factor structure presented several secondary loadings. Factor solutions of four factors for 15 and 13 facets were similar in both samples and other cross-cultural factor analysis conducted with the oblique pattern matrix, but not with the structure matrix. The goodness-of-fit indices obtained by CFA wereunsatisfactory when the simple structure was analyzed. To obtain satisfactory results, it was necessary to incorporate the salient loadings and correlated error terms, as thestandard procedurein personality structureresearch. Models including thoseparameters werehighly congruent across coun- tries. The multigroup analyses showed that the 13-facet TEIQue struc- ture was very similar in the Catalan and the English data. Overall, the TEIQue psychometric properties were comparable and robust in both samples and consequently the instrument can be recommended for psychological researchand practice.

\section{Appendices}

Appendix 1

TEIQue descriptives, sex and country differences in Catalan and English samples and alpha reliabilities.

\begin{tabular}{|c|c|c|c|c|c|c|c|c|c|c|c|c|c|c|c|c|c|}
\hline & \multicolumn{8}{|c|}{ Catalan sample } & \multicolumn{8}{|c|}{ English sample* } & \multirow{2}{*}{$\begin{array}{l}\text { Catalan } \\
\text { vs } \\
\text { English }\end{array}$} \\
\hline & \multicolumn{2}{|c|}{$\begin{array}{l}\text { Females } \\
(\mathrm{n}=174)\end{array}$} & \multicolumn{2}{|c|}{$\begin{array}{l}\text { Males } \\
(\mathrm{n}=177)\end{array}$} & \multirow[b]{2}{*}{$d$} & \multicolumn{3}{|c|}{$\begin{array}{l}\text { All } \\
(\mathrm{n}=351)\end{array}$} & \multicolumn{2}{|c|}{$\begin{array}{l}\text { Females } \\
(\mathrm{n}=907)\end{array}$} & \multicolumn{2}{|c|}{$\begin{array}{l}\text { Males } \\
(\mathrm{n}=759)\end{array}$} & \multirow[b]{2}{*}{$d$} & \multicolumn{3}{|c|}{$\begin{array}{l}\text { All } \\
(\mathrm{n}=1666)\end{array}$} & \\
\hline & M & SD & M & SD & & M & SD & $\alpha$ & M & SD & M & $\mathrm{SD}$ & & M & SD & $\alpha$ & $d$ \\
\hline Age & 39.47 & 15.26 & 40.27 & 16 & -.05 & 39.87 & 15.62 & - & 27.10 & 10.64 & 32.67 & 12.70 & -.48 & 29.65 & 11.95 & - & .79 \\
\hline Adaptability & 4.20 & .78 & 4.26 & .77 & -.08 & 4.23 & .77 & .63 & 4.56 & .84 & 4.73 & .85 & -.20 & 4.65 & .85 & .75 & -.50 \\
\hline Assertiveness & 4.69 & .80 & 4.89 & .72 & -.26 & 4.79 & .77 & .59 & 4.72 & .93 & 5.05 & .88 & -.36 & 4.89 & .93 & .77 & -.11 \\
\hline Emotion expression & 4.78 & 1.25 & 4.35 & 1.20 & .35 & 4.56 & 1.24 & .87 & 4.87 & 1.23 & 4.58 & 1.19 & .24 & 4.74 & 1.22 & .89 & -.02 \\
\hline Emotion management & 4.55 & .94 & 4.56 & .96 & -.10 & 4.56 & .95 & .73 & 4.75 & .79 & 4.99 & .83 & -.30 & 4.87 & .82 & .70 & -.37 \\
\hline Emotion perception & 5.03 & .76 & 4.75 & .88 & .34 & 4.89 & .83 & .71 & 4.89 & .78 & 4.77 & .85 & .15 & 4.84 & .81 & .73 & .06 \\
\hline Emotion regulation & 4.26 & .85 & 4.39 & .89 & -.15 & 4.32 & .87 & .78 & 4.13 & .87 & 4.66 & .85 & -.61 & 4.39 & .90 & .72 & -.08 \\
\hline Empathy & 5.35 & .82 & 5.02 & .84 & .40 & 5.18 & .85 & .71 & 5.22 & .74 & 4.99 & .80 & .30 & 5.12 & .77 & .70 & .08 \\
\hline Happiness & 5.71 & .91 & 5.61 & 1.01 & .11 & 5.66 & .96 & .83 & 5.57 & 1.01 & 5.50 & 1.03 & .07 & 5.55 & 1.01 & .87 & .01 \\
\hline Impulse control & 4.68 & .84 & 4.65 & .88 & .04 & 4.67 & .86 & .64 & 4.47 & .93 & 4.60 & .92 & .18 & 4.54 & .93 & .74 & .14 \\
\hline Optimism & 5.15 & .98 & 5.18 & .96 & -.03 & 5.16 & .97 & .79 & 5.25 & .98 & 5.25 & .96 & 0 & 5.26 & .97 & .80 & -.11 \\
\hline Relationships & 5.63 & .74 & 5.41 & .73 & .30 & 5.52 & .74 & .61 & 5.60 & .75 & 5.32 & .82 & .36 & 5.48 & .79 & .68 & .04 \\
\hline Self-esteem & 4.87 & .88 & 5.02 & .84 & -.17 & 4.95 & .86 & .78 & 4.77 & .89 & 5.09 & .86 & -.37 & 4,92 & .89 & .80 & .03 \\
\hline Self-motivation & 4.98 & .72 & 4.92 & .74 & .08 & 4.95 & .73 & .63 & 4.70 & .81 & 4.77 & .82 & -.09 & 4.74 & .81 & .69 & .26 \\
\hline Social awareness & 4.83 & .80 & 4.75 & .86 & .09 & 4.79 & .83 & .77 & 4.93 & .87 & 5.08 & .91 & -17 & 5.01 & .89 & .82 & -.25 \\
\hline Stress management & 4.29 & .90 & 4.52 & .85 & -.26 & 4.41 & .88 & .73 & 4.30 & 1.00 & 4.82 & .89 & -.55 & 4.55 & .98 & .81 & -.15 \\
\hline Emotionality & 5.20 & .67 & 4.88 & .74 & .48 & 5.04 & .73 & .89 & 5.13 & .68 & 4.92 & .73 & .30 & 5.05 & .71 & .78 & -.01 \\
\hline Self-control & 4.41 & .73 & 4.52 & .74 & -.15 & 4.47 & .74 & .87 & 4.26 & .76 & 4.69 & .74 & -.57 & 4.49 & .79 & .79 & -.03 \\
\hline Sociability & 4.69 & .71 & 4.74 & .72 & -.07 & 4.95 & .86 & .86 & 4.77 & .72 & 5.04 & .76 & -.36 & 4.92 & .75 & .82 & .04 \\
\hline Well-being & 5.24 & .81 & 5.27 & .85 & -.04 & 5.26 & .83 & .91 & 5.19 & .83 & 5.28 & .83 & -.11 & 5.24 & .83 & .83 & .02 \\
\hline Global trait EI & 4.87 & .56 & 4.82 & .58 & .09 & 4.84 & .57 & .95 & 4.82 & .57 & 4.95 & .61 & -.22 & 4.90 & .59 & .90 & -.10 \\
\hline
\end{tabular}

Note: * In the English data 74 subjects no informed of the age. The means and standard deviation of theage is calculated for 863 females and 729 males $(\mathrm{n}=1592)$. 
Appendix 2

Pearson correlations for the 15 TEIQue facets and the global score

(Catalan data above the diagonal and English data are below the diagonal).

\begin{tabular}{|c|c|c|c|c|c|c|c|c|c|c|c|c|c|c|c|c|c|}
\hline & & 1 & 2 & 3 & 4 & 5 & 6 & 7 & 8 & 9 & 10 & 11 & 12 & 13 & 14 & 5 & 16 \\
\hline 1 & Adaptability & - & .31 & .32 & .30 & .31 & .50 & .36 & .41 & .30 & .42 & .47 & .36 & .45 & .50 & .54 & .63 \\
\hline 2 & Assertiveness & .36 & - & .35 & .54 & .33 & .26 & .19 & .34 & .20 & .38 & .36 & .19 & .53 & .64 & .32 & .61 \\
\hline 3 & Emotion expression & .31 & .31 & - & .43 & .58 & .07 & .38 & .47 & .06 & .29 & .38 & .48 & .37 & .55 & .17 & .62 \\
\hline 4 & Emotion management & .32 & .54 & .35 & - & .38 & .19 & .36 & .29 & .08 & .24 & .31 & .26 & .46 & .63 & .27 & .57 \\
\hline 5 & Emotion perception & .36 & .44 & .64 & .49 & - & .21 & .50 & .36 & .31 & .34 & .45 & .53 & .37 & .49 & .31 & .73 \\
\hline 6 & Emotion regulation & .42 & .18 & .12 & .06 & .24 & - & .29 & .25 & .52 & .40 & .41 & .30 & .40 & .32 & .68 & .54 \\
\hline 7 & Empathy & .37 & .26 & .40 & .42 & .54 & .18 & - & .26 & .17 & .32 & .42 & .49 & .26 & .46 & .35 & .62 \\
\hline 8 & Happiness & .44 & .38 & .42 & .31 & .48 & .31 & .41 & - & .26 & .46 & .73 & .61 & .55 & .50 & .40 & .76 \\
\hline 9 & Impulse control & .15 & .24 & .22 & .04 & .31 & .50 & .26 & .27 & - & .50 & .30 & .40 & .32 & .29 & .52 & .49 \\
\hline 10 & Self-motivation & .39 & .34 & .31 & .13 & .41 & .31 & .26 & .50 & .34 & - & .51 & .44 & .49 & .39 & .36 & .61 \\
\hline 11 & Optimism & .47 & .46 & .37 & .33 & .33 & .38 & .27 & .74 & .27 & .47 & - & .46 & .56 & .49 & .49 & .78 \\
\hline 12 & Relationships & .40 & .25 & .45 & .24 & .46 & .23 & .52 & .51 & .38 & .40 & .43 & - & .33 & .42 & .34 & .71 \\
\hline 13 & Self-esteem & .43 & .47 & .36 & .36 & .46 & .37 & .32 & .64 & .39 & .49 & .67 & .52 & - & .57 & .44 & .76 \\
\hline 14 & Social awareness & .48 & .56 & .54 & .61 & .51 & .38 & .44 & .46 & .26 & .46 & .53 & .44 & .60 & - & .38 & .77 \\
\hline 15 & Stress management & .47 & .28 & .21 & .21 & .27 & .68 & .24 & .41 & .47 & .45 & .50 & .48 & .49 & .44 & - & .66 \\
\hline 16 & TEIQue total & .67 & .61 & .64 & .57 & .64 & .59 & .55 & .71 & .55 & .67 & .72 & .63 & .74 & .79 & .68 & - \\
\hline
\end{tabular}

Appendix 3

Fit indices for the oblique models in the Catalan and English data.

\begin{tabular}{|c|c|c|c|c|c|c|c|c|c|c|c|}
\hline \multicolumn{12}{|c|}{ Catalan data $(\mathrm{n}=351)$} \\
\hline \multicolumn{2}{|c|}{ Model } & $x^{2}$ & d.f. & $\chi^{2} /$ d.f & RMR & GFI & TLI & CFI & RMSEA & LO & $\mathrm{HI}$ \\
\hline \multirow[t]{2}{*}{15 facets } & Full-1 factor & 594.39 & 87 & 8.63 & .17 & .82 & .78 & .81 & .13 & .12 & .14 \\
\hline & 4-factors & 473.52 & 83 & 5.70 & .08 & .86 & .82 & .86 & .12 & .11 & .13 \\
\hline \multirow{6}{*}{13 facets } & 4_factors_SL & 344.62 & 73 & 4.72 & .06 & .89 & .86 & .90 & .10 & .09 . & .11 \\
\hline & 4_factors_SL $+r$ & 243.56 & 69 & 3.53 & .05 & .92 & .90 & .94 & .08 & .07 & .10 \\
\hline & Full-1 factor & 482.51 & 62 & 7.78 & .18 & .84 & .78 & .82 & .14 & .13 & .15 \\
\hline & 4 -factors & 359.14 & 59 & 6.09 & .07 & .87 & .83 & .88 & .12 & .10 & .13 \\
\hline & 4_factors_SL & 162.98 & 47 & 3.47 & .06 & .88 & .85 & .91 & .12 & .10 & .14 \\
\hline & 4_factors_SL $+r$ & 121.17 & 43 & 2.84 & .05 & .91 & .90 & .94 & .10 & .08 & .12 \\
\hline \multicolumn{12}{|c|}{ English data $(\mathrm{n}=1.666)$} \\
\hline \multicolumn{2}{|c|}{ Model } & $\chi^{2}(\mathrm{c})$ & d.f. & $\chi^{2} /$ d.f & RMR & GFI & TLI & CFI & RMSEA & LO & $\mathrm{HI}$ \\
\hline \multirow[t]{4}{*}{15 facets } & Full-1 factor & 2239.15 & 87 & 25.74 & .14 & .85 & .79 & .83 & .12 & .12 & .13 \\
\hline & 4 -factors & 1823.21 & 84 & 21.70 & .08 & .88 & .83 & .86 & .11 & .11 & .12 \\
\hline & 4_factors_SL & 1162.27 & 76 & 15.29 & .05 & .92 & .88 & .91 & .09 & .09 & .10 \\
\hline & 4_factors_SL + r & 918.83 & 74 & 12.42 & .05 & .94 & .91 & .93 & .08 & .08 & .09 \\
\hline \multirow[t]{4}{*}{13 facets } & Full-1 factor & 1717.22 & 62 & 27.70 & .15 & .87 & .80 & .86 & .13 & .12 & .13 \\
\hline & 4 -factors & 1246.06 & 59 & 21.12 & .07 & .90 & .85 & .90 & .11 & .10 & .12 \\
\hline & 4_factors_SL & 815.00 & 55 & 14.81 & .05 & .93 & .90 & .93 & .09 & .09 & .10 \\
\hline & 4_factors_SL $+r$ & 672.68 & 52 & 12.94 & .04 & .94 & .91 & .94 & .09 & .08 & .09 \\
\hline
\end{tabular}

Note: $x^{2}$ : Chi squared; d.f.: Degrees of Freedom. RMR: Root Mean square Residual. GFI: Goodness of Fit Index. TLI: Tucker-Lewis Index.

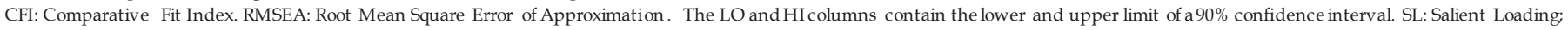

SL_r $=$ Salient Loadings + correlated errors. $\chi^{2}$ : The associated $p$ values were always lower than .0001 .

Appendix 4

Fit indices for theoblique models in the multi-group analyses.

\begin{tabular}{|c|c|c|c|c|c|c|c|c|c|c|}
\hline & Catalan & nodel & $\mathrm{SL}+1$ & & & & & & & \\
\hline Model & $x^{2}$ & d.f. & $\chi^{2} /$ d.f & RMR & GFI & TLI & CFI & RMSEA & LO & $\mathrm{HI}$ \\
\hline Multigroup A & 843.61 & 86 & 9.809 & .04 & .94 & .90 & .94 & .07 & .06 & .07 \\
\hline Multigroup B & 876.64 & 96 & 9.132 & .05 & .94 & .90 & .94 & .06 & .06 & .07 \\
\hline $\begin{array}{l}\text { Multigroup } C \\
\text { English } 13 \text { facets model }\end{array}$ & $\begin{array}{l}\text { 956.79 } \\
\text { (4_factor }\end{array}$ & 121 & 7.907 & .06 & .94 & .92 & .94 & .06 & .06 & .06 \\
\hline Multigroup A & 974.22 & 104 & 9.37 & .04 & .93 & .90 & .93 & .06 & .06 & .07 \\
\hline Multigroup B & 989.99 & 113 & 8.76 & .05 & .93 & .91 & .93 & .06 & .06 & .07 \\
\hline Multigroup C & 1032.46 & 126 & 8.19 & .06 & .93 & .91 & .93 & .06 & .06 & .06 \\
\hline
\end{tabular}

Note: $\chi^{2}$ : Chi squared; d.f.: Degrees of Freedom. RMR: Root Mean square Residual. GFI: Goodness of Fit Index. TLI: Tucker-Lewis Index.

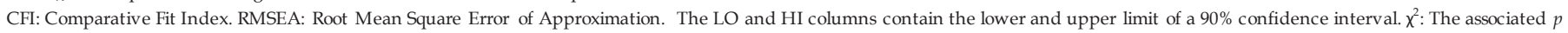
values were always lower than .0001 . 


\section{References}

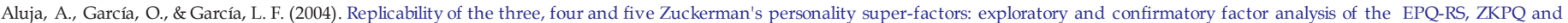
NEO-PI-R. Personality an Individual Differences, 36, 1093-1108.

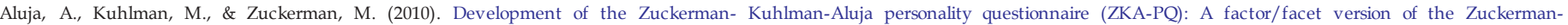
Kuhlman personality questionnaire (ZKPQ). Journal of Personality Assessment, 92, 416-431.

Bar-On, R. (1997). Bar-On Emotional Quotient Inventory: Technical manual. Toronto: Multi- Health Systems Inc.

Blanch, A., \& Aluja, A. (2009). Work, family and personality: A study of work-family con-

flict. Personality and Individual Differences, 46, 520-524.

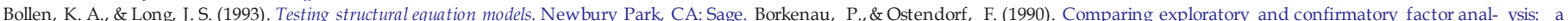
Differences, $11,515-524$ study on the 5-factor model of personality. Personality and Individual

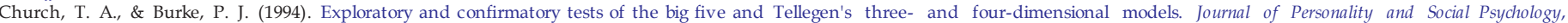
66, 93-114.

Goleman, S. (1995). Emotional Inteligence: Why ot can Matter More than IQ. London: Bloomsbury.

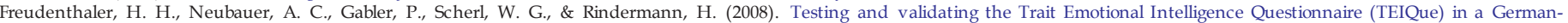
speaking sample. Personality and Individual Differences, 45, 673-678.

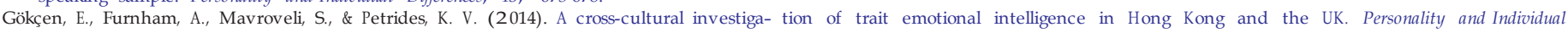
Differences, 65, 30-35.

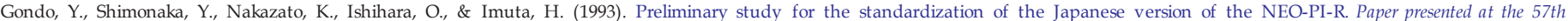
Meeting of the Japanese Psychological Association, Tokyo.

Gorsuch, R. L. (1982). Factor Analysis (2nd ed.). Hillsdale NJ: Erlbaum.

Hamblet on, R. K. (2001). The next generation of the ITC test translation and adaptation guidelines. European Journal ofPsychological Assessment, 17, 164-172.

Hu, L., \& Bentler, P. M. (1995). Evaluating model fit. In R. H. Hoyle (Ed.), Structural equa- tion modeling: concepts, issues, and applications. Newbury Park, CA: Sage.

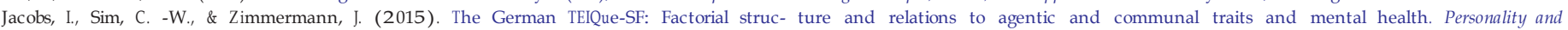
Individual Differences, 72, 189-194

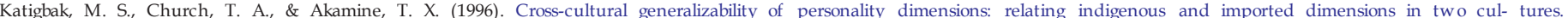
Journal of Personality and Social Psychology, 70, 99-114.

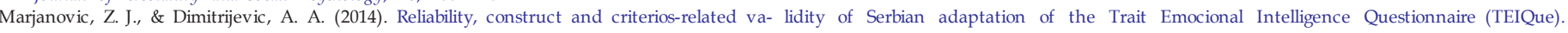
Psicológica, 47, 249-262 


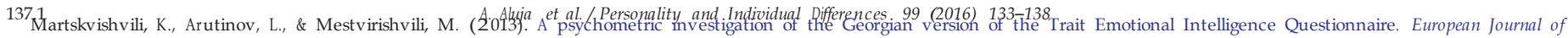
Personality Assessment, 29, 84-88.

Mayer, J., Caruso, D., \& Salovey, P. (1999). Emotional intelligence meets traditional stan- dards for and intelligence. Intelligence, $27,267-298$.

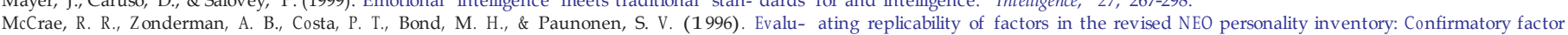
analysis versus Procrustes rotation. Journal of Personality and Social Psychology, 70, 552-566.

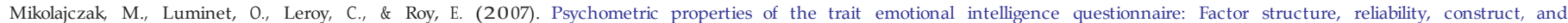
incremental validity in a French-speaking population. Journal of Personality Assessment, 88, 338-353.

Personality and Individual Differences, 42, 883-891.

Mulaik, S. (2007). There is a place for approximate fit in structural equation modelling.

Petrides, K. V. (2001). A psychometric investigation into the construct of emotional intelli- gence. Unpublished doctoral dissertation University College London.

Petrides, K. V. (2009a). Psychometric properties of the Trait Emotional Intelligence Ques- tionnaire (TEIQue). In C.Stough, D. H.Saklofske, \& J. D. A. Parker (Eds.), Assessing emo- tional intelligence: theory, research, and applications. New York: Springer pp. XI, 364 p. Petrides, K. V., \& Furnham, A. (2003). Trait emotional intelligence. Behavioural validation in two studies Journal of Personality, 17, 39-57

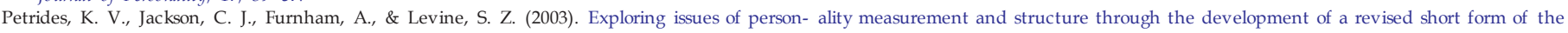
Eysenck Personality Profiler. Journal of Personality Assessment, 81, 272-281.

Petrides, K. V., Pita, R., \& Kokkinaki, F. (2007). The location of trait emotional intelligence in personality factor space. British Journal of Psychology, 98, 273-289.

Rolland, J. P., Parker, W. D., \& Stumpf, H. (1998). A psychometric examination of the French translations of the NEO-PI-R and NEO-FFI. Journal of Personality Assessment, 71, 269-291. Salovey, Personality, 9, 185-211.

P., \& y Mayer, J. D. (1990). Emotional intelligence. Imagination, Cognition, and

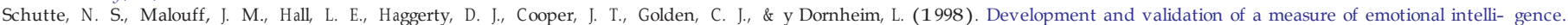
International Journal of Research into Structure and Development of Personality, and the Causation of Individual Differences, 25, 167-178.

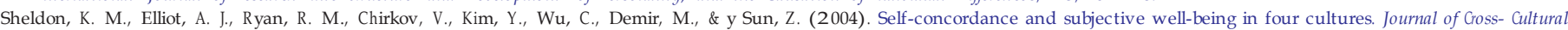
Psychology, 35, 209-233.

Terracciano, A. (2003). The Italian version of the NEO-PI-R: Conceptual and empirical sup- port for the use of targeted rotation. Personality and Individual Differences, 35, 1859-1872.

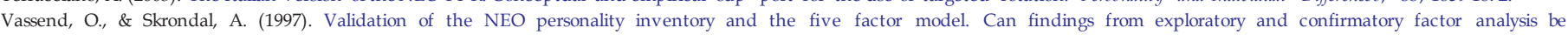
reconciled? European Journal of Personality, 11, 147-166. 